\title{
Condom Using Perception Among Sex-Buying Men in India
}

\author{
Koustuv Dalal ${ }^{1, ~ *, ~ J a h a n ~ S h a b n a m ², ~ A n i m e s h ~ B i s w a s ~}{ }^{1}$ \\ ${ }^{1}$ Department of Public Health Science, School of Health and Medical Sciences, Örebro University, Örebro, Sweden \\ ${ }^{2}$ Independent Researcher, Copenhagen, Denmark
}

Email address:

koustuv2010@hotmail.com (K. Dalal)

\section{To cite this article:}

Koustuv Dalal, Jahan Shabnam, Animesh Biswas. Condom Using Perception Among Sex-Buying Men in India. Science Journal of Public Health. Vol. 3, No. 6, 2015, pp. 820-824. doi: 10.11648/j.sjph.20150306.14

\begin{abstract}
Aims: The study explores condom use among sex-buying men in India. The study also identifies the level of knowledge regarding the contraction of sexually transmitted diseases (STD's) and AIDS in relation to condom use. Methods: The observational study has designed in where purposively 156 Men were selected who reported that they paid for sex and used a condom during in the last 12 months. Respondents were from 29 Indian states during 2005-2006. Descriptive analysis was performed using SPSS Statistics version 20.0 for window for statistical analysis. Results: Majority of sex buyers were found in between 25-34 years age group, middle and higher income group were found more to buy sex than poor group. $77 \%$ of the participants used condoms every time they had paid sex with the female partner, majority of men had a good knowledge on AIDS ( $89 \%$ ) and $78.8 \%$ has a believe that condom using can reduce risk of contaminated with HIV. Conclusion: Middle aged men in India with a high socio-economic status and educational background have a better perception, knowledge and attitude towards using condom during sex buying and have knowledge on HIV, however low poverty level men are vulnerable and they are expose to contamination with HIV AIDS.
\end{abstract}

Keywords: AIDS, Condom Use Behavior, India, Sex-Buying Men, STD

\section{Introduction}

HIV/AIDS is one of the most epidemic public health challenges facing the world today $(1,2)$. With a prevalence of near one percent, globally 33 million people are now living with HIV/AIDS $(1,3)$. Lack of adequate access to HIV prevention and treatment services creates $6800 \mathrm{HIV}$ infected persons and 5700 deaths every day.

The highest burden of HIV is in Africa. Data from 2007 indicates that 2.5 million people were infected and 2.1 million died in Sub Saharan Africa. However, Asian countries are now seeing an increase in HIV infections (4). In Asian countries, HIV is mainly transmitted through commercial sex working men and women, using injectable drugs and women HIV positive transmitting the disease to their children (5).

In India, HIV is a health burden for the country, epidemic is concentrated among vulnerable group at high risk for HIV (6). In 2007, around $1.8-2.9$ million people suffered with HIV in India (7). While there is a geographical distribution of HIV in India, more people are affected in the in industrial areas $(7,8)$. Religious and custom barriers to having sex before marriage has caused a raised high demand of commercial sex (9) Furthermore, using a condom for protection against contamination of HIV is not commonplace, causing an increase of risk of occurring HIV in the mass population (8-10). (8).

One of the studies found that about $50 \%-70 \%$ of clients of female sex workers are either married or have another female partner (11). This causes a larger sexual network with increasing vulnerability of HIV/STD (12). Low level of knowledge regarding safe sex, educational level, sex with more than one partner are still dominant factors linked to spreading the disease in India $(14,15,16)$.

Several studies have been conducted to identify the knowledge and attitude towards HIV/AIDS and condom using behaviour in the general population in different settings (17). However, there is inadequate focus concerning male clients of female sex workers who are playing one of key role in transmission of disease (18). While, a wide range of diversity of the male client across the country made difficult to recognize properly (19).

This study has explored condom using behaviour among the sex-buying men in India and also identified the knowledge of sexual transmitted diseases, which is now curtail to know for further intervention. 


\section{Methods}

We have conducted a cross sectional study. The sample was taken from the national family health survey (NFHS-3) of 29 member states in India during 2005-06. The NFHS-3 survey used multistage sampling methods. Indian 2001 census was used to determine the sample size from each area. Samples were taken from rural and urban areas and conducted in different stages.

In rural areas sampling was performed in two steps. In the first step using PPS, primary sampling units (PSUs) were selected in villages. Then households were randomly selected within each PSU. In the urban areas sample selections were performed in three steps: In the first step, municipality wards were selected using PPS. Then from each sample ward census enumeration blocks (CEB) were randomly selected. Finally within the selected CEB households were randomly selected. Each of the interviews was taken face to face maintaining confidentiality. A detailed description of the sampling procedure, study design and data collection are reported elsewhere (20).

The study randomly selected 74,369 men aged 15-64 years from the NFHS-3 survey where structured pre-tested questionnaire was used to conduct the face to face interview. All participants were asked about their sex habits and if they paid sex or not. If yes, then they were included for further information. 156 men reported they paid for sex during last 12 months and were included for the analysis.

Condom using during paid sex was taken as a dependent variable, whereas; age group, residency, education, occupation, economic status and the number of partners were chosen as independent variable. In order to measure the economic status, we have used a previously established wealth index theory in which a composite measure of the cumulative living standard of a household including all economic assets are included. Economic status included; poorest, poorer, medium, richer and richest strata (21). Descriptive analysis was performed using SPSS Statistics version 20.0 for window for statistical analysis.

\section{Ethical approval}

Ethical permission was received from the Institutional review Board of Opinion Research Corporation (ORC), Macro International Incorporated. Informed written consent was obtained from the participants prior starting the survey.

\section{Results}

Overall 47\% male uses condom during paid sex in the past 12 months. Male sex buyers, aged between 25-34 years represents highest proportions of condom use during their last paid sex session. Proportions of urban males (condom users) are more than rural males during sex buying episodes (52\% vs. $48 \%$ ). Secondary educated males (56\%), working men $(92 \%)$ demonstrate highest proportions of condom use during paid sex. Males belonging to richer (25\%) and richest (27\%) economic stratum, with high standard of living (42\%) dominate condom use during paid sex. Men with single partner $(56 \%)$ proportionally use more condom than their peers with no partner $(41 \%)$ or multiple partners $(3 \%)$. Nonsmoking (74\%) and alcoholic (66\%) males use more condom than smokers and non-alcoholic males during paid sex.

Table 1. Individual and family characteristics of sex buying men.

\begin{tabular}{|c|c|}
\hline Category & Used condom for last paid sex \\
\hline \multicolumn{2}{|l|}{ Age } \\
\hline $115-19$ & $15(9.6 \%)$ \\
\hline $220-24$ & $42(26.9 \%)$ \\
\hline $325-29$ & $24(15.4 \%)$ \\
\hline $430-34$ & $24(15.4 \%)$ \\
\hline $535-39$ & $22(14.1 \%)$ \\
\hline $640-44$ & $13(8.3 \%)$ \\
\hline $745-49$ & $10(6.4 \%)$ \\
\hline $850-54$ & $6(3.8 \%)$ \\
\hline \multicolumn{2}{|l|}{ Residency } \\
\hline Urban & $81(51.9 \%)$ \\
\hline Rural & $75(48.1 \%)$ \\
\hline \multicolumn{2}{|l|}{ Education } \\
\hline No Education & $24(15.4 \%)$ \\
\hline Primary & $27(17.3 \%)$ \\
\hline Secondary & $88(56.4 \%)$ \\
\hline Higher & $17(10.9 \%)$ \\
\hline \multicolumn{2}{|c|}{ Currently working } \\
\hline No & $8(5.1 \%)$ \\
\hline Yes & $147(92.4 \%)$ \\
\hline \multicolumn{2}{|l|}{ Economic status } \\
\hline Poorest & $21(13.5 \%)$ \\
\hline Poorer & $25(16 \%)$ \\
\hline Middle & $29(18.6 \%)$ \\
\hline Richer & $39(25 \%)$ \\
\hline Richest & $42(26.9 \%)$ \\
\hline \multicolumn{2}{|c|}{ Standard of living } \\
\hline Low & $29(18.6 \%)$ \\
\hline Middle & $48(30.8 \%)$ \\
\hline High & $66(42.3 \%)$ \\
\hline \multicolumn{2}{|c|}{ Number of partners } \\
\hline No & $64(41 \%)$ \\
\hline One & $87(55.8 \%)$ \\
\hline More than one & $5(3.2 \%)$ \\
\hline \multicolumn{2}{|l|}{ Smoking } \\
\hline No & $116(74.4 \%)$ \\
\hline Yes & $40(25.6 \%)$ \\
\hline \multicolumn{2}{|l|}{ Alcohol } \\
\hline No & $53(34 \%)$ \\
\hline Yes & $103(66 \%)$ \\
\hline
\end{tabular}

We have also explored the knowledge and attitude of the male sex buyers. Most of the men (90\%) have previous knowledge of sexually transmitted diseases (STD's) and AIDS (89\%). Majority of the participants (78\%) are aware about spared of contamination not having sex at all, on the other hand $79 \%$ males believe that condom using can reduce the risk of spreading of disease contamination. More than half $(51 \%)$ of the participants accept wife's/ partner's autonomy for asking condom use during their personal sex life. 
Table 2. Knowledge and attitude of sex buying men.

\begin{tabular}{lc}
\hline & $\begin{array}{c}\text { Used condom for } \\
\text { last paid sex }\end{array}$ \\
\hline Know about STD & $15(9.6 \%)$ \\
No & $141(90.4 \%)$ \\
Yes & $17(10.9 \%)$ \\
Know about AIDS & $139(89.1 \%)$ \\
No & \\
Yes & $34(21.8 \%)$ \\
Reduce risk of getting AIDS not having sex at all & $122(78.2 \%)$ \\
No & \\
Yes & $33(21.2 \%)$ \\
Reduce risks of AIDS by using condoms during sex & $123(78.8 \%)$ \\
No & \\
Yes & $14(9 \%)$ \\
Wife /partner can ask for using condom & $142(51 \%)$ \\
No & \\
Yes &
\end{tabular}

\section{Discussion}

We have reviewed 156 men who paid for sex with female partners in last 12 months. Most of them were middle aged who were involved in sex buying. Studies showed that the proportion of sex buying widely differs in different counties. Spain has reported the highest rate in Europe with 39\%, whereas Asian countries considerably increased in sex buying, $73 \%$ of Thai men buy sex (23). However, different methodologies have been adopted to estimate the prevalence of paid sex in different regions (12). In our study, the involvement of middle aged men paying for sex caused a higher risk of contamination with HIV/ADIS. One study in India showed that commercial sex in the southern part of India comprises of about $\$ 8.7$ billion per year $(6,24)$ which increases the risk of HIV infection without proper condom use and eventually that leads to poverty, deprivation and economic instability (25). The current study indicates poor condom use behaviour among sex buying men (47\%). Therefore considering the health and socioeconomic burden, we should initiate appropriate program for ameliorating condom use, especially during sex-buying episodes.

In the present study, $47 \%$ of the respondents used condom they had paid sex during previous one year. However, another study mentioned using condoms is very low in India (10) compared to European countries with a higher level of condom use for protection $(26,27)$. Social workers in India are trying to get condoms more widely used, but sex workers are in a fear of losing their customers if they insist (26) since it is perceived to interfere with the clients' pleasure of sex (28). So the taboo for such 'condom non-pleasure myth' should be thwarted out. Another concern may be the quality of condom. The low-cost/ freely available government sponsored condoms may be thick, unpleasant and not thin enough for sexual pleasure. Another study for 'condom nonpleasure myth' could be interesting to explore the actual reason.

In a Dutch study many clients reported that consistent condom use did not view safer sex as an intrinsic choice, but rather as something forced on them by the sex worker. Therefore, the authors identified that the importance of extrinsic motivation to safer sex practices for HIV prevention, sex workers must be supported in their insistence on condom use (30). A study in Pune in India included over 400 women at STD clinics, 93\% were married and 91\% had never sex with anyone else except their husband, but all of them were infected, $13.6 \%$ were HIV positive (31).

While, our study shows that the male has a higher level of knowledge about AIDS and STDs, moreover the majority of them had attitude towards using condom. They were aware that condoms could reduce the chance of contracting AIDS in around $79 \%$ cases. Although a study conducted in India mentioned that HIV prevalence was highest among women whose husbands were travelling because of their employment in the transport industry (7). Our study also showed that educating groups engaging in buying sex of those who were also working group in majority case and had economic solvency in many cases. Like in many other countries, the unequal power relationship between men and women, in India, there is lower level of education and status of women and risky behaviour of the male partners consequently leads to difficulties to achieve safe sex, within marriage or in commercial sex $(2,8)$.

Another study illustrated that if women were trying to gain knowledge about safe sex from partners, parents or teachers, or purchasing condoms they are treated as promiscuous (13). On the other hand, efforts have been made to support women to take more control over their reproductive and health status, promoting a community-oriented approach to HIV/AIDS intervention $(32,33)$.

From a multi-level approach that includes individual, community and societal interventions (34), to using models that work in specific risk situations (35). The successes of Senegal, Thailand and Uganda to reduce the HIV/AIDS transmission rates can also be used to determine and analyse factors that works (36). A more effective result could be explored through visiting sex-selling areas, where the sex buying men are higher in number and are more likely to response to the related issues (29).

Our study provided a brief idea on how men have perceived and in which group. Experiences from other countries can be implies to make changes among the male to use condom for safety.

\section{Conclusion}

Middle aged men in India with a high socio-economic status and educational background have a better perception, knowledge and attitude towards using condom during sex buying, however the lower socio-economic group are still vulnerable. The study also tried to elicit the importance of female education, knowledge about safe sex and using condoms to improve the HIV status of the country.

However, a further study is required to understand how females, including sex workers, want to be involved in improving condom use and moreover, an interventional study 
can be designed on a small scale with the findings.

\section{References}

[1] UNAIDS/WHO. AIDS epidemic update: December 2007. Geneva. http://data.unaids.org/pub/EPISlides/2007/2007_epiupdate_en. pdf.

[2] Mawar N, Sahays, Pandit A, Mahajan U. The third phase of HIV pandemic: Social consequences of HIV/AIDS stigma and discrimination and future needs. Indian J. Med. Res. 2005; 122: $471-484$.

[3] Epidemiological fact sheet on HIV and AIDS. World Health Organization, Geneva, 2008 http://www.who.int/globalatlas/predefinedReports/EFS2008/f ull/EFS2008_IN.pdf.

[4] Global HIV prevalence has leveled off. World Health Organization, Geneva, 2009. http://www.who.int/mediacentre/news/releases/2007/pr61/en/i ndex.html.

[5] Overview of AIDS and HIV in Asia. Accessed 12 March 2014 Available: http://www.avert.org/aids-asia.htm.

[6] Moon K. Knowledge, perceptions, attitudes and practices of HIV/AIDS: A comparative study of behavior change in commercial sex workers and truck drivers in the dindigul and coimbatore districts of Tamil Nadu, India. C. Pap. Inter. Dev. 2002; 6: 2-5.

[7] HIV Sentinel Surveillance and HIV Estimation in India 2007: A technical brief. http://www.nacoonline.org/upload/Publication/M\&E\%20Surv eillance, $\% 20$ Research/HIV\%20Sentinel\%20Surveillance $\% 20$ a nd\%20HIV\%20Estimation\%202007_A\%20Technical\%20Brie f.pdf.

[8] HIV/AIDS South Asia- understanding and responding. The World Bank, 2008 http://web.worldbank.org/WBSITE/EXTERNAL/COUNTRIE S/SOUTHASIAEXT/0,,contentMDK:21019386 pagePK:146 736 piPK:146830 theSitePK:223547,00.html.

[9] Gray LA, Devdas RP, Vijaylakshmi O, Kamalanathank G. Knowledge, attitudes, and beliefs about HIV/AIDS among Hindu students from a government women's college of South India. Intern. J. Adv. Counseling, 1999; 21: 207-219.

[10] Subramanian T, Gupte MD, Paranjape RS, Brahmam GN, Ramakrishnan L. HIV, sexually transmitted infections and sexual behaviour of male clients of female sex workers in Andhra Pradesh, Tamil Nadu and Maharashtra, India: Results of a cross-sectional survey. AIDS, 2008; 5: S69-S79.

[11] Chandrasekaran PG, Dallabetta V, Loo S, et al. Containing HIV/AIDS in India: The unfinished agenda. Lancet Infect. Dis., 2006; 6: 508-521.

[12] Carael M, Slaymaker E, Lyerla R, Sarkar S. Clients of sex workers in different regions of the world: Hard to count. Sex. Transm. Infec., 2006; 82: 26-33.

[13] Motzoi C. Combating HIV/AIDS: Promoting Gender Equality among Youth. World Bank: Washington DC. 2006. http://www.athgo.org/downloads/position_papers/Motzoi_Clai rneige.pdf.
[14] Sudha RT, Vijay DT, Lakshmi V. Awareness, attitudes and beliefs of the general public towards HIV/Aids in Hyderabad, a capital city from South India. Indian J. Med. Sci.,2005; 59: 307-316.

[15] Lowndes CM, Alary M, Labbe AC, et al. Interventions among male clients of female sex workers in Benin, West Africa: An essential component of targeted HIV preventive interventions. Sex. Transm. Infect. 2007; 83: 577-581.

[16] Blankenshipa KM, Wesr BS, Kershawc TS, Biradavolu MR. Power, community mobilization and condom use practices among female sex workers in Andhra Pradesh, India. AIDS, 2008; 22: S109-S116.

[17] McManus A, Dhar L. Study of knowledge, perception and attitude of adolescent girls towards STIs/HIV, safer sex and sex education: A cross sectional survey of urban adolescent school girls in South Delhi, India. BMC Women's Health, 2008; 8: 12.

[18] Couture MC, Soto JC, Akom E, et al. Clients of female sex workers in gonaives and st-marc, haiti characteristics, sexually transmitted infection prevalence and risk factors. Sex. Transm. Dis., 2008; 35: 849-855.

[19] Remple VP, Patrick DM, Johnston C, et al. Clients of indoor commercial sex workers: Heterogeneity in patronage patterns and implications for HIV and STI propagation through sexual networks. Sex. Transm. Dis., 2007; 34:754-760.

[20] IIPS, 2007. Calverton, Maryland, USA. India: DHS, 2005/2006-Final Report.

[21] Rutstein S, Johnson K. The DHS wealth index. DHS Comparative Reports No. 6. Calverton, ORC Macr, Maryland, USA, 2004.

[22] Leridon H, Zesson G, Hubert M. The Europeans and their sexual partners. In: Sexual Behaviour and HIV/AIDS in Europe, Hubert, M., N. Bajos and T. Sandfort (Eds.). UCL Press, London, 1998: P: 442.

[23] Anderson B, O'Connell DJ. Is trafficking in human beings demand driven? A multi-country pilot study. Geneva: International Organization for Migration. 2003.

[24] Hwang A. 2001. AIDS has arrived in India and China. World Watch, http://www.amazon.com/Arrived-speculationpandemic-Statistical-Included/dp/B0008I3UDS.

[25] Cohen D. The HIV epidemic and sustainable human development. Issues Paper No. 29, UNDP, 1997. http://www.hivpolicy.org/Library/HPP000243.pdf.

[26] Ward H, Day S, Weber J. Risky business: Health and safety in the sex industry over a 9 year period. Sexually Transmitted Infections, 1999; 75: 340-343.

[27] Ward H, Day S, Geen A, Cooper K, Weber J. Declining prevalence of STI in the London sex industry, 1985-2002. Sex. Transm. Infect.2004; 80: 374-376.

[28] Randolph ME, Pinkerton SD, Bogart LM, et al. Sexual pleasure and condom use. Arch. Sex Behav. 2007, 36, 844-848.

[29] Morris M, Podhisita C, Wawer MJ, Handcock MS. Bridge Population in the spread of HIV/AIDS in Thailand. AIDS, 1996; 10: 1265-127.

[30] De Graaf R, Zessen I, Vanwesenbeeck CJ, Straver CJ, Visser $\mathrm{JH}$. Condom use by dutch men with commercial heterosexual contacts: Determinants and considerations. AIDS Educ. Prev., 1997; 9: 411-23. 
[31] UNAIDS/WHO, 1998. AIDS epidemic update: December 1998. http://data.unaids.org/Publications/IRCpub06/epiupdate98_en.pdf.

[32] Heise LL, Elias C. Transforming aids prevention to meet women's needs: A focus on developing countries. Soc. Sci. Med., 1995; 40: 931-943.

[33] Ulin PR. African women and AIDS: Negotiating behavioral change. Soc. Sci. Med., 1992; 34: 63-73.

[34] Waldo CR, Coates TJ. Multiple levels of analysis and intervention in HIV prevention science: exemplars and directions for new research. AIDS, 2000; 2: S18-S26.
[35] Dole LR, Elkins DB, Boonjear K, Phiensrithom S, MatickaTyndale E. Cattle markets and local festivals: Development of HIV/AIDS prevention interventions for specific risk situations in rural northeast Thailand. Health Place, 1998; 4: 265-272.

[36] UNAIDS, 1999. HIV prevention needs and successes: A tale of three countries. An Update on HIV Prevention Success in Senegal, Thailand and Uganda. http://data.unaids.org/Publications/IRC-pub02/jc535-hi_en.pdf. 